\title{
Localized photodeposition of catalysts using nanophotonic resonances in silicon photocathodes
}

\author{
Evgenia Kontoleta, Sven H. C. Askes, Lai-Hung Lai and Erik C. Garnett ${ }^{\star}$
}

\section{Full Research Paper}

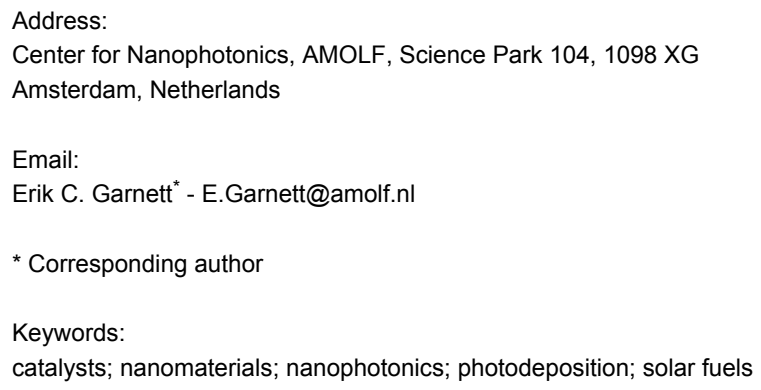

Beilstein J. Nanotechnol. 2018, 9, 2097-2105. doi:10.3762/bjnano.9.198

Received: 09 April 2018

Accepted: 16 July 2018

Published: 03 August 2018

This article is part of the thematic issue "Nano- and microstructures for energy conversion: materials and devices".

Guest Editors: M. Schmid and H. Mönig

(c) 2018 Kontoleta et al.; licensee Beilstein-Institut. License and terms: see end of document.

\begin{abstract}
Nanostructured semiconductors feature resonant optical modes that confine light absorption in specific areas called "hot spots". These areas can be used for localized extraction of the photogenerated charges, which in turn could drive chemical reactions for synthesis of catalytic materials. In this work, we use these nanophotonic hot spots in vertical silicon nanowires to locally deposit platinum nanoparticles in a photo-electrochemical system. The tapering angle of the silicon nanowires as well as the excitation wavelength are used to control the location of the hot spots together with the deposition sites of the platinum catalyst. A combination of finite difference time domain (FDTD) simulations with scanning electron microscopy image analysis showed a reasonable correlation between the simulated hot spots and the actual experimental localization and quantity of platinum atoms. This nanophotonic approach of driving chemical reactions at the nanoscale using the optical properties of the photo-electrode, can be very promising for the design of lithography-free and efficient hierarchical nanostructures for the generation of solar fuels.
\end{abstract}

\section{Introduction}

The relentless rise of $\mathrm{CO}_{2}$ levels in the atmosphere as well as the growth of the world population remind us of the importance of finding new, clean pathways to cover our energy needs. Fuel generation from renewable energy resources could be one of the "clean" approaches for meeting our energy requirements. Although, sunlight is the most abundant source of green energy, its long-term storage is required, due to daily and yearly fluctu- ations. The most promising medium for stable, high-density storage is in the form of chemical energy, such as $\mathrm{H}_{2}$ or organic compounds, by using photochemical fuel generators [1-4].

In the center of a photochemical fuel generator are the photoelectrodes, where light absorption and conversion to chemical energy take place. The photo-electrodes are in contact with an 
electrolyte that is the primary source of fuel together with the sunlight. In such a system, light absorption by the electrodes leads to the creation of electron-hole pairs, which after their separation participate in chemical reactions in the electrolyte to make fuels. One example is water splitting for $\mathrm{H}_{2}$ generation $[5,6]$. Carefully designed photo-electrodes are necessary for low cost and high efficiency, which are both needed to make solar fuels competitive with fossil fuels as an energy carrier. Nanostructuring the main photoactive material, e.g., a semiconductor, has proven to be a promising method for increasing the efficiency of solar fuel generation $[7,8]$. The higher surface to volume ratio in nanostructured semiconductors ensures the use of less material, reduces the requirements on current density and often increases light absorption. This increased light absorption comes from optical resonances in nanomaterials, which have been studied extensively in both metallic (plasmonic) and dielectric material systems [9-13]. One hallmark of resonant absorption is the appearance of localized "hot spots". In particular, semiconducting nanostructures can sustain Mie-like leaky modes due to their high refractive index and the occurrence of multiple internal light reflections from the boundaries of the structure $[9,13]$. However, in vertical nanowires under normalincidence illumination, Mie modes cannot be excited and instead coupling to waveguide modes (e.g., the $\mathrm{HE}_{11}$ ) and subsequent Fabry-Perot cavity interference play the dominant role in creating these hot spots $[14,15]$. The highly concentrated electric fields at the hot spots lead to elevated concentrations of photogenerated charge carriers that can be used to drive solar fuel reactions [16-19]. Additionally, photochemical fuel generators require a catalyst, such as platinum, to lower the overpotential to drive the chemical reaction $[2,7,20-24]$. The catalyst would be ideally located at the semiconductor-solution interface, directly at the location of the hot spots.

Placing the catalyst exclusively at the hot spots would reduce both the catalyst loading (lowering the cost) and the average time between charge generation and chemical reaction (increasing the efficiency). However, current catalysts are simply randomly placed on semiconductor photo-electrodes with an optimized average density [20,24,25]. Photodeposition of the catalytic material with photogenerated charges from excited semiconductors has been also achieved but without a good control over the deposition sites [26-31]. An exception is the work of Li et al. [27], where charge separation was achieved at different crystal facets of $\mathrm{BiVO}_{4}$ nanocrystals for selective photodeposition of metal and metal oxide catalytic nanoparticles. Nevertheless, this method for the moment is limited to this specific material and structure.

Here we present a different approach in which localized nanophotonic resonances in semiconductors are used to place cata- lyst particles exactly where they are needed. We show that the location of catalyst deposition on vertical silicon nanowires can be tuned by adjusting their shape (tapering angle) or changing the excitation wavelength. The experimentally observed deposition profiles match reasonably well with optical simulations of the photogenerated charge carrier distribution for each shape and wavelength. Most notably, deposition profiles far from those expected from a simple Beer-Lambert law have been obtained, in contrast to previous related work on silicon microwires [32,33]. Our results provide the first step for rationally designed catalyst positioning using the underlying resonant properties of nanoscale photocatalysts, tunable simply by altering the shape, size or excitation wavelength. The extensive literature on such nanophotonic tuning makes this an exciting approach for lithography-free nanoscale control over catalyst positioning [34-38].

We have chosen vertical silicon nanowires as a model nanophotonic system because of their ease of fabrication, known optical constants and broad spectral absorption range. In presence of a Pt-catalyst precursor $\left(\mathrm{H}_{2} \mathrm{PtCl}_{6}\right)$ in a three-electrode photo-electrochemical system (Figure 1), photogenerated electrons reach the surface of the silicon nanowires, reducing the precursor to form metallic platinum nanoparticles $(\operatorname{Pt}(0))$. The position of the Pt deposition can be controlled by adjusting the tapering angle or the incident wavelength. The platinum photodeposition results are observed with a scanning electron microscope (SEM) and compared with the output of finite difference time domain (FDTD) simulations of the density distribution of the photogenerated carriers within the silicon nanostructures.

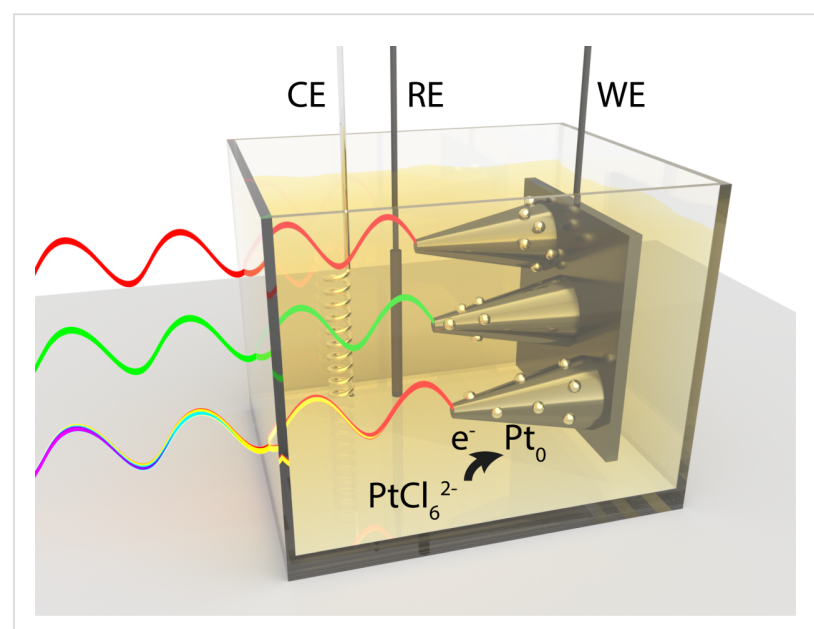

Figure 1: Schematic illustration of the photo-electrochemical deposition of metallic Pt on silicon nanostructures from hexachloroplatinate $\left(\mathrm{PtCl}_{6}{ }^{2-}\right)$ in a three-electrode photo-electrochemical cell with counter electrode (CE), reference electrode (RE) and working electrode (WE). The location of catalyst deposition can be tuned by adjusting the excitation wavelength from red to green to white, or (not shown) the nanostructure shape. 


\section{Results and Discussion}

\section{Fabrication of silicon nanostructures and calculation of their optical modes}

Silicon nanostructures were fabricated by etching a p-type silicon substrate using a combination of $\mathrm{Cl}_{2}$ and $\mathrm{HBr} / \mathrm{O}_{2}$ plasmas with $110 \mathrm{~nm}$ diameter $\mathrm{SiO}_{2}$ spheres being used as etch mask. Tuning the ratio of the $\mathrm{HBr} / \mathrm{O}_{2}$ plasmas allowed for vertical nanowires with variable sidewall tapering angle (see details in Experimental section and Figure S1, Supporting Information File 1). Vertical nanocones (height $\approx 720 \mathrm{~nm}$, top diameter $\approx 60 \mathrm{~nm}$, bottom diameter $\approx 160 \mathrm{~nm}$, angle $\approx 15^{\circ}$ ), inverted nanocones (height $\approx 1 \mu \mathrm{m}$, top diameter $\approx 70 \mathrm{~nm}$, base diameter $\approx 120 \mathrm{~nm}$ and smallest diameter $\approx 60 \mathrm{~nm}$ ) and nanowires (height $\approx 790 \mathrm{~nm}$, diameter $\approx 80 \mathrm{~nm}$ ) were fabricated here and subsequently used to tune the distribution of photogenerated carriers (Figure 2). An $18 \mathrm{~nm}$ amorphous $\mathrm{TiO}_{2}$ layer was conformally deposited on the silicon nanostructures by using atomic layer deposition (ALD). This layer assists with charge separation, stabilizes the silicon surface and helps to passivate trap states, leading to well-known improvements in photo-electrochemical performance [39-41]. The amorphous $\mathrm{TiO}_{2}$ layer was further annealed at $350{ }^{\circ} \mathrm{C}$ for $3 \mathrm{~h}$ to form crystalline anatase $\mathrm{TiO}_{2}$, which led to an improved performance. The final $\mathrm{TiO}_{2}$ layers were characterized with X-ray diffraction (XRD) (Figure S2, Supporting Information File 1) and ellipsometry

a)

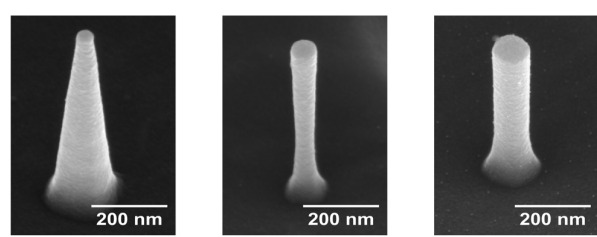

b)

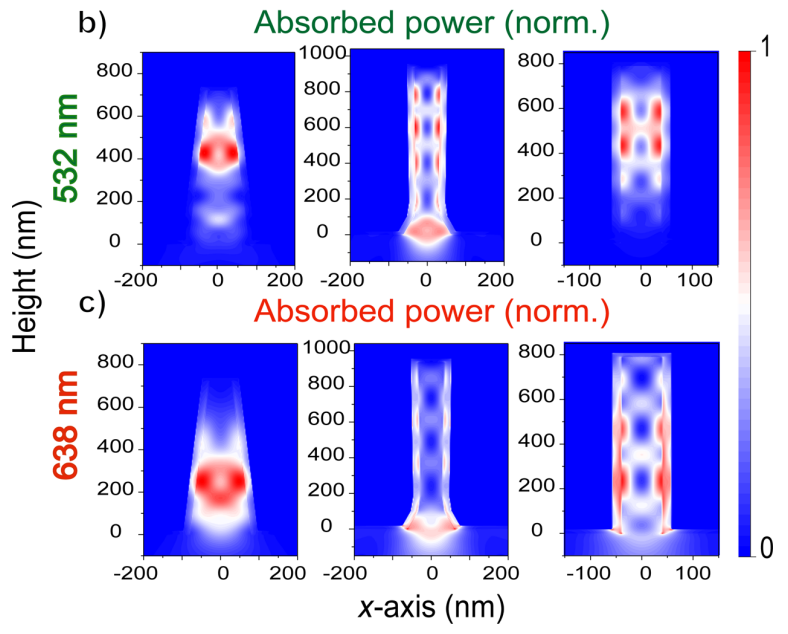

Figure 2: (a) SEM images of a silicon nanocone (left), an inverted nanocone (middle) and a nanowire (right) coated with an $18 \mathrm{~nm} \mathrm{TiO} 2$ layer. The tapering angle was controlled by varying the $\mathrm{Cl}_{2}$ and $\mathrm{HBr} / \mathrm{O}_{2}$ flow rates during plasma etching. (b, c) FDTD simulations of absorbed power in each nanostructure at (b) $532 \mathrm{~nm}$ and (c) $638 \mathrm{~nm}$ normalized to the maximum value.
(Figure S3, Supporting Information File 1) to verify their quality. Both the XRD pattern and optical constants ( $n$ and $k$ values) matched the literature values for thin anatase $\mathrm{TiO}_{2}$ films [42].

The photocarrier density distribution under monochromatic illumination (532 or $638 \mathrm{~nm}$ ) in the $\mathrm{Si}-\mathrm{TiO}_{2}$ nanostructures was simulated using the FDTD method. It was assumed that every absorbed photon was converted to an electron-hole pair and only the optical effects were taken into account in the simulations. The dimensions of the average silicon nanostructures extracted from SEM images were used for the simulations, while the $n$ and $k$ values measured with ellipsometry were used for the $\mathrm{TiO}_{2}$ coating. Every structure was simulated on a thick silicon substrate, also coated with $18 \mathrm{~nm} \mathrm{TiO}_{2}$, and the surrounding refractive index was set to 1.33 to resemble the aqueous conditions of the reaction environment. The simulations show the cross-sectional absorbed power profiles (normalized to the maximum value per plot) of the three different silicon nanostructures, for excitation at $532 \mathrm{~nm}$ (Figure 2b) and $638 \mathrm{~nm}$ (Figure 2c). The location of the hot spots depends on the excitation wavelength and the shape of the nanostructure. Silicon nanocones confine light mostly at the top of the structure at $532 \mathrm{~nm}$ (Figure 2b) in contrast to an excitation at $638 \mathrm{~nm}$, where most of the light is absorbed at the bottom of the cone (Figure 2c). In the case of inverted nanocones, light is concentrated primarily at the bottom for both wavelengths, although at $532 \mathrm{~nm}$ there are also additional hot spots along the height. In silicon nanowires, hot spots are present at the top and the middle of the structure for $532 \mathrm{~nm}$ but for excitation at $638 \mathrm{~nm}$, more hot spots appear. Overall, the results of these simulations confirm the presence of distinct hot spots in the nanostructures and enable us to investigate whether the simulated hot spots match the location of the deposited catalytic material after illumination.

\section{Photodeposition of platinum}

A three-electrode photo-electrochemical cell, electrically connected with a potentiostat, was used for deposition of the platinum catalyst on the nanostructures. The sample served as the working electrode (WE) with a platinum wire counter electrode (CE) and $\mathrm{Ag} / \mathrm{AgCl}$ reference electrode (RE) (Figure 1). During a typical photo-electrodeposition experiment, the sample was mounted in direct contact with a Pt-precursor electrolyte (4 mM H $\mathrm{PtCl}_{6}, \mathrm{pH} \mathrm{11)}$ and the current flow to the working electrode was recorded as a function of time at a constant electrochemical potential, i.e., in the chronoamperometry mode. The samples had an open-circuit voltage potential of around $-0.1 \mathrm{~V}$ (vs $\mathrm{Ag} / \mathrm{AgCl}$ ) and were biased by $700 \mathrm{mV}$ to a more reducing potential of $-0.8 \mathrm{~V}(\mathrm{vs} \mathrm{Ag} / \mathrm{AgCl})$ during deposition, to efficiently extract the photogenerated charges from the 
Si nanostructures into the electrolyte and enhance the kinetics of the reaction. The flat-band potential of $\mathrm{TiO}_{2}$ at $\mathrm{pH} 11$ is above the conduction band edge of p-type silicon, so $\mathrm{TiO}_{2}$ acts as an electron blocking layer here $[5,43,44]$. Therefore, the presence of $\mathrm{TiO}_{2}$ offers a control over the potential we could apply to selectively promote photodeposition while avoiding electrodeposition. In the absence of a $\mathrm{TiO}_{2}$ layer the recorded dark current is much higher than the corresponding photocurrent (Figure S4a, Supporting Information File 1), which means that the electrons reaching the electrolyte by biasing the samples dominate over the photogenerated ones. SEM images (Figure S5, Supporting Information File 1) show the homogenous formation of platinum nanoparticles both on the Si nanostructures and on the substrate, when the samples were illuminated without the $\mathrm{TiO}_{2}$ layer but still under biased conditions. The final potential value $(-0.8 \mathrm{~V})$ for photo-electrodeposition of platinum nanoparticles in the presence of a $\mathrm{TiO}_{2}$ layer was chosen because it yields a high current ratio between illumination and dark conditions (Figure S6, Supporting Information File 1). Even more negative potentials than $-0.8 \mathrm{~V}$ could be used here, but it was not necessary since the kinetics of the reaction were fast enough to drive the photo-electrodeposition in a few seconds. Typically, the current was 75-200 times greater with illumination than without. As shown in Figure 3b, during the first $20 \mathrm{~s}$ of a typical photo-electrodeposition experiment using $532 \mathrm{~nm}$ light, the laser beam was blocked and the current was recorded. As soon as the laser beam hit the sample, a current increase was observed due to the contribution of the photogenerated charges. After an electrical charge of around $1.35 \mathrm{mC}$ was passed to the illuminated sample, the laser beam was blocked again and the measurement was stopped.

The area of the laser beam $\left(0.06 \mathrm{~mm}^{2}\right.$ for $532 \mathrm{~nm}$ and $0.35 \mathrm{~mm}^{2}$ for $638 \mathrm{~nm}$ ) was much smaller than the surface of the samples in contact with the electrolyte $\left(0.3 \mathrm{~cm}^{2}\right)$, which allowed straightforward identification of the illuminated area and discrimination of platinum deposition under light and dark conditions in the same experiment (Figure S7, Supporting Information File 1). SEM images (Figure 3a and Figure S8, Supporting Information File 1) taken from the illuminated region revealed the presence of new nanoparticles on the silicon nanostructures and substrate. These were not observed far from the illuminated region (Figure S9, Supporting Information File 1), which confirmed that the irradiation had caused the formation of nano- a)

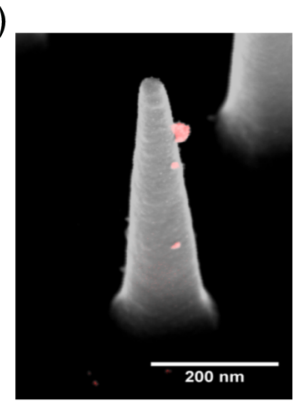

b)

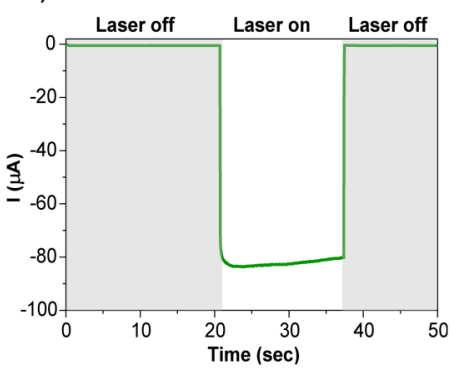

d)

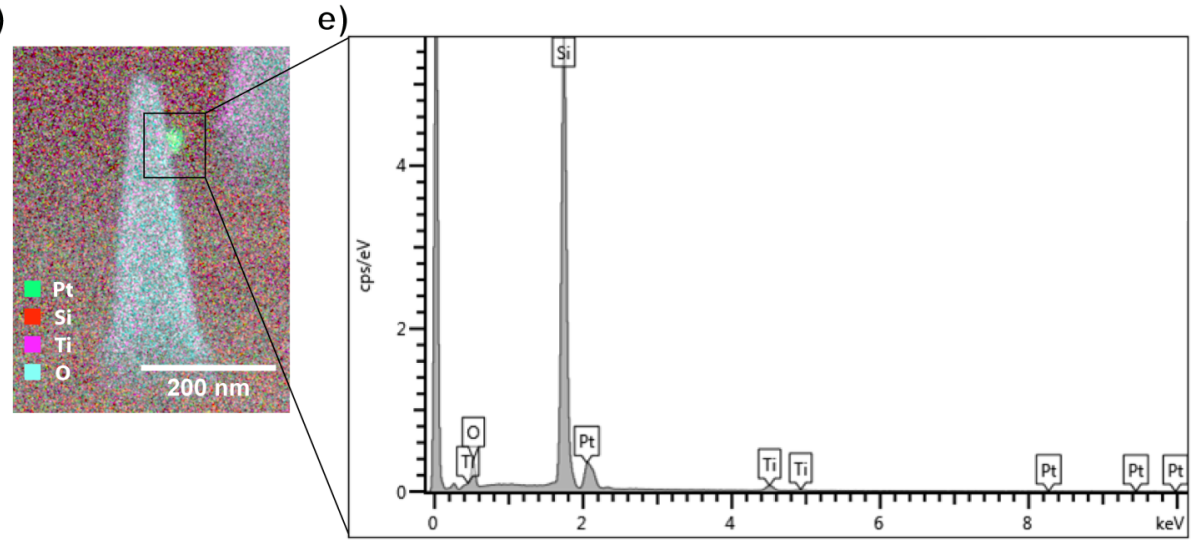

Figure 3: a) An overlay image of a backscattered electron (red; in-lens mirror detector) and secondary electron (grey; through-the-lens detector) SEM image of a silicon nanocone after photo-electrodeposition of platinum. b) Current as a function of the time during a photo-electrodeposition experiment of silicon nanocones excited at $532 \mathrm{~nm}$ (laser on), at $-0.8 \mathrm{~V}$ applied potential in an aqueous solution of $\mathrm{H}_{2} \mathrm{PtCl}_{6}(\mathrm{pH} 11)$. c) X-ray photoemission spectrum of photo-electrodeposited platinum on silicon nanostructures (blue) compared with the spectrum of a metallic Pt reference material (red). d) EDS elemental map where each color indicates a different element: Pt (green), Si (red), Ti (purple) and O (cyan). e) Elemental map retrieved from an individual deposited particle (100 pA beam current, $10 \mathrm{kV}$ acceleration beam voltage). 
particles. Energy-dispersive X-ray spectrometry (EDS) mapping clearly confirmed the presence of platinum, when an individual newly formed particle was analyzed (Figure 3d and Figure 3e). Furthermore, the oxidation state of platinum was investigated with X-ray photo-electron spectroscopy (XPS) on a sample with a higher amount of photo-electrodeposited platinum (ca. $2 \mathrm{mC}$ ). The observed platinum $4 f_{7 / 2}$ and $4 f_{5 / 2}$ binding energy peaks corresponded very well to those of a metallic Pt reference material (Figure 3c). Overall, these results demonstrate that light can be used as an external stimulus for the formation of catalytic $\operatorname{Pt}(0)$ material on Si nanostructures.

\section{Correlation of hot spots and $\mathrm{Pt}$ deposition sites}

Next, a comparison was made between the Pt deposition sites and the simulated optical hot spots of the Si nanostructures with an SEM image analysis approach, as follows: First, preliminary chronoamperometric experiments were conducted to indicate the conditions in which we could easily identify the location of the platinum particles on each nanostructure without the total overgrowth of the latter. A total amount of around $1 \mathrm{mC}$ was needed to obtain well separated Pt particles with a diameter of $11 \mathrm{~nm}$, which typically corresponded to $15-20 \mathrm{~s}$ of illumination at 532 or $638 \mathrm{~nm}$ with a light intensity of $1.2 \mathrm{~W} / \mathrm{cm}^{2}$ or $0.35 \mathrm{~W} / \mathrm{cm}^{2}$, respectively. The size of the deposited platinum nanoparticles was selected only for particle identification purposes and further optimization of the photo-electrodeposition process is necessary for the fabrication of efficient photocatalytic samples. For each Si nanostructure morphology, overlays of secondary-electron and backscattered-electron (collected with an in-lens mirror detector) SEM images were acquired. This overlay method facilitates the identification of platinum nanoparticles based on the high electron backscattering efficiency of this heavy element (Figure 4a and Figures S10-S12, Supporting Information File 1). Images were collected from 100 individual nanostructures of each morphology while exclusively considering structures with dimensions within half a standard deviation of the average structure. Furthermore, platinum particles with a diameter below $6 \mathrm{~nm}$ were excluded, as they could also originate from electrodeposition (Figure S9, Supporting Information File 1). The volume of each Pt nanoparticle was estimated and converted to the corresponding number of platinum atoms. Finally, histograms were made to visualize the deposited amount of $\mathrm{Pt}$ as a function of the Si nanostructure height (Figure $4 \mathrm{~b}$ and Figure $4 \mathrm{c}$ ). The results are presented together with the simulated integrated absorbed power (normalized to the maximum value per plot) along the height of every structure at 532 and $638 \mathrm{~nm}$.

Comparison of the platinum deposition distribution on the silicon nanostructures and the integrated absorbed power

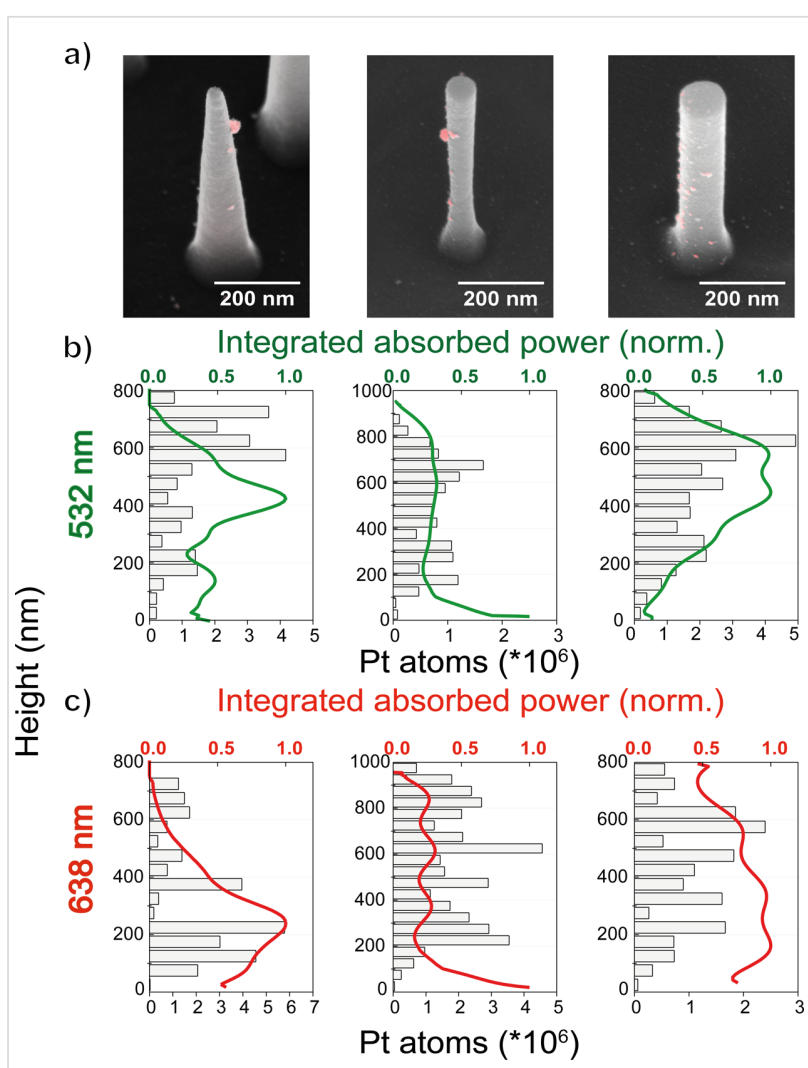

Figure 4: (a) Overlay images of backscattered electron (red) and secondary-electron (grey) SEM images after photo-electrodeposition of platinum on a silicon nanocone (left), inverted nanocone (middle), and nanowire (right). (b, c) Total amount of platinum atoms deposited (grey bars) along the height of each silicon structure for excitations at (b) $532 \mathrm{~nm}$ and (c) $638 \mathrm{~nm}$. Each graph includes the accumulated values of 100 structures. Green and red solid lines correspond to the integrated absorbed power (normalized to the maximum value) as a function of the height at $532 \mathrm{~nm}$ and $638 \mathrm{~nm}$, respectively.

profiles reveals that they match reasonably. Specifically, for silicon nanocones a correlation of the platinum deposition sites and the optical modes is shown for both excitation wavelengths with some deviations. At $532 \mathrm{~nm}$, the two peaks of the platinum distribution are slightly shifted towards larger heights, while at $638 \mathrm{~nm}$ deposition of platinum is also observed in locations not expected from the absorbed power simulations, i.e., at the top of the nanostructure. In the case of inverted nanocones, the platinum deposition profiles seem to follow the profiles of the integrated absorbed power. However, simulations showed that most of the light is absorbed at the bottom of the nanostructure, where no platinum is observed in the experiments. In contrast, deposition of the catalytic material occurs primarily at a height of around 200-300 nm from the bottom. This discrepancy may be explained by the fact that both nanocones and inverted nanocones exhibit structural diameter differences along their height, which could lead to differences in carrier collection efficiency if the diffusion length is of the order of, or smaller than, the diameter. Such variations in carrier collection 
efficiency would naturally alter the final deposition distribution in a manner qualitatively consistent with our observations. Finally, silicon nanowires excited at $532 \mathrm{~nm}$ concentrate the incident light mostly at the top or the middle of the structure, corresponding well with the platinum deposition analysis. For $638 \mathrm{~nm}$ excitation, the same structures exhibited multiple deposition sites along their height, which is also correlated to the integrated absorbed power peaks.

Instead of the formation of new small particles of platinum on the silicon nanostructures, overgrowth of the already deposited ones was noticed from the SEM images (Figures S10-S12, Supporting Information File 1). This effect could be explained by the fact that platinum nanoparticles act as electron-trapping centers on the surface of $\mathrm{TiO}_{2}[45,46]$. After the formation of the very first platinum nanoparticles, photogenerated electrons from the silicon nanostructures are transferred to $\mathrm{TiO}_{2}$ and in sequence to the already formed platinum. The Schottky barrier between $\mathrm{TiO}_{2}$ and platinum nanoparticles does not allow for a "back" transfer of electrons. Hence, charge separation is promoted, which allows further reduction of hexachloroplatinate to $\operatorname{Pt}(0)$ on one of the existing platinum nanoparticles rather than in new locations. As a result, the initial platinum nanoparticle formation may alter the final deposition profile from the simulated one by prohibiting the deposition at other parts of the nanostructrure. As mentioned earlier, an external electric field is applied to the samples for more efficient extraction of the photogenerated charges. This electric field is not taken into account in the simulated distribution of the charges along the height of the Si nanostructures (Figure 2), and this is another factor that could affect the localization of the photoelectrodeposition. The platinum deposition could also be broadened compared to the simulated profile due to our method of measuring the height of each particle, which extracts 3D distances from a 2D image. Noise could also be introduced by the $\mathrm{TiO}_{2}$ layer itself. Although $\mathrm{TiO}_{2}$ has a shorter electron diffusion length compared to silicon $[47,48]$, the $\mathrm{TiO}_{2}$ surface could also have randomly distributed surface sites with higher catalytic activity, leading to preferential deposition, or traps that capture carriers preventing deposition.

\section{Conclusion}

We show that the optical modes of silicon nanostructures can be used for lithography-free patterning of catalytic nanoparticles. Tuning of the photo-electrochemical formation of platinum nanoparticles along the height of silicon nanostructures was achieved by changing either the shape (tapering angle) of the silicon nanostructures or the excitation wavelength (red or green light). This method utilizing the optical modes of semiconducting nanostructures to pattern catalytic materials with nanoscale control can be a very promising method for an easy and low-cost fabrication of efficient photo-electrodes. It provides a lot of flexibility on the materials involved and on the design of the final structure. Further research should be focused on improving the positioning precision and implementing the approach in a state-of-the art photo-electrode/catalyst system in order to demonstrate the potential for solar fuel production enhancement.

\section{Experimental General}

Chemicals were purchased from major chemical suppliers and used as received. Scanning electron microscopy (SEM) was performed on a FEI Verios 460 with a typical acceleration beam voltage of $5 \mathrm{kV}$ and $100 \mathrm{pA}$ beam current. Secondary-electron images were collected with a through-the-lens detector (TLD) and backscattered-electron images were collected with an in-lens mirror detector. Energy dispersive X-ray spectrometry (EDS) was performed with an Oxford Instruments device with an acceleration beam voltage of $10 \mathrm{kV}$ and beam current of 100 pA. X-ray diffraction was done with a Bruker D2 Phaser with $\mathrm{Cu} \mathrm{K \alpha}$ radiation $(\lambda=1.5418 \AA)$.

\section{Simulations}

Lumerical FDTD Solutions was used for simulations of single silicon nanostructures on a $3.5 \times 3.5 \times 2 \mu \mathrm{m}$ silicon substrate. Absorbed power simulations were conducted with an $18 \mathrm{~nm}$ $\mathrm{TiO}_{2}$ layer, with refractive index values ( $n$ and $k$ ) retrieved from ellipsometry (Figure S3, Supporting Information File 1). An example of the simulation environment can be found in Figure S13 (Supporting Information File 1) in which the case of inverted nanocones is presented. The structures were excited with a plane wave source with wavelengths of 400-1100 nm and the absorbed power was retrieved from an absorption per unit volume monitor with wavelength selection option. The refractive index of the surrounding medium was set to 1.33 . The mesh size in the FDTD simulations was equal to $2 \times 2 \times 2 \mathrm{~nm}$ for all the structures.

\section{Fabrication of silicon nanostructures}

Silicon p-type samples (Active Business Company $\mathrm{GmbH}$, $<100>$ orientation ) $12 \times 12 \mathrm{~mm}$, with $1-10 \Omega \cdot \mathrm{cm}$ resistivity, were used as substrates for the fabrication of the three different types of silicon nanostructures. First, the samples were cleaned with soap and consecutively rinsed with copious amounts of water, acetone and isopropanol. After that, the samples were submerged in hot piranha solution $\left(120^{\circ} \mathrm{C}, 3: 1\right.$ concentrated $\mathrm{H}_{2} \mathrm{SO}_{4} / 30 \% \mathrm{H}_{2} \mathrm{O}_{2}$ ) for 20 min and rinsed with deionized water. Then $2-3 \mu \mathrm{L}$ of $110 \mathrm{~nm}$ diameter $\mathrm{SiO}_{2}$ spheres dispersed in ethanol were drop-cast on the clean silicon samples and annealed for $1 \mathrm{~min}$ at $60{ }^{\circ} \mathrm{C}$ on a hot plate. The samples were etched with a combination of plasmas (PlasmaPro 100 Cobra 
ICP Etch). First $\mathrm{Cl}_{2}(20 \mathrm{sec}, 50 \mathrm{sccm}$, HF forward power $40 \mathrm{~W}$, $7 \mathrm{mTorr}$ ) was used for removal of the native oxide and then $\mathrm{HBr} / \mathrm{O}_{2}(5 \mathrm{~min}$ for nanocones and $11 \mathrm{~min}$ for nanowires and inverted nanocones, HF forward power $30 \mathrm{~W}, 7 \mathrm{mTorr}$ ) was used for etching the silicon to the desired structures. Before the etching steps an oxygen cleaning step was used (1 min and $30 \mathrm{sec}, 50 \mathrm{sccm} \mathrm{O}$, HF forward power $60 \mathrm{~W}$, ICP forward power $100 \mathrm{~W}, 6 \mathrm{mTorr})$. The temperature used for all the steps of the plasma etching was $20^{\circ} \mathrm{C}$. The ratio of $\mathrm{HBr} / \mathrm{O}_{2}$ was very crucial for the control of the shape of the silicon structures. For the nanocones a ratio of $48.2: 1.8 \mathrm{sccm}\left(\mathrm{HBr} / \mathrm{O}_{2}\right)$ was chosen, 49.5:0.5 for inverted nanocones and 49:1 for stand-up nanowires. The ICP forward power during $\mathrm{Cl}_{2}$ and $\mathrm{HBr} / \mathrm{O}_{2}$ etching was $750 \mathrm{~W}$ for silicon nanocones and nanowires, and $600 \mathrm{~W}$ for inverted nanocones. After etching, the samples were treated with 7 vol \% HF solution for the removal of $\mathrm{SiO}_{2}$ formed during the etching procedure, rinsed with water, dipped in hot piranha solution for $20 \mathrm{~min}$ and rinsed one more time with water. The last step (hot piranha solution) proved necessary to obtain a smooth coating of the structures with $\mathrm{TiO}_{2}$, probably due to the increase of the hydrophilicity.

\section{Formation of $\mathrm{TiO}_{2}$ using atomic layer deposition}

A custom-built atomic layer deposition system was used for the deposition of thin and compact $\mathrm{TiO}_{2}$ layers on the silicon nanostructures. For $18 \mathrm{~nm} \mathrm{TiO}_{2}$ layers, subsequent injection of MilliQ water $\left(18.2 \mathrm{M} \Omega \cdot \mathrm{cm}\right.$ ) and $99.995 \% \mathrm{TiCl}_{4}$ (for $10 \mathrm{~ms}$ each) took place in a vacuum chamber with a delay of $18 \mathrm{~s}$ between each injection. The samples were heated by a copper stage at $100{ }^{\circ} \mathrm{C}$. The base pressure of the system was below $5 \cdot 10^{-2}$ mbar. The pressure during deposition was adjusted to 1.1 mbar using an $\mathrm{N}_{2}$ purging flow to remove the formed gases and excess precursors. Post-annealing of the samples in a tube oven, in air, at $350{ }^{\circ} \mathrm{C}$ for $3 \mathrm{~h}$ with a ramp of $11^{\circ} \mathrm{C} / \mathrm{min}$ was needed for the formation of anatase $\mathrm{TiO}_{2}$ (Figure S2, Supporting Information File 1).

\section{Photo-electrochemical deposition}

For the deposition of platinum nanoparticles, a photo-electrochemical cell (Zahner Scientific Instruments, PECC-1, slightly modified) made from Teflon was used (Figure S14, Supporting Information File 1). The cell has three inputs for the three different electrodes (working, reference and counter). Only a small area $\left(0.3 \mathrm{~cm}^{2}\right)$ of the working electrode (i.e., the sample) was in contact with the electrolyte, which was illuminated through a quartz window. The electrolyte consisted of an aqueous solution of chloroplatinic acid $(4 \mathrm{mM})$ and $\mathrm{Na}_{2} \mathrm{SO}_{4}(0.1 \mathrm{M})$, with the $\mathrm{pH}$ value adjusted to 11 with $2 \mathrm{M} \mathrm{NaOH}$. The back contact of the sample consisted of $4 \mathrm{~nm}$ of chromium and $50 \mathrm{~nm}$ of gold deposited with a double-target sputter coater (Leica EM
ACE600). The electrical connections of the sample with the potentiostat (BioLogic Science Instruments, SP-200) were made using conductive aluminum tape (Advance Tapes AT521) adhered to the back metal contact of the sample, which was not in contact with the electrolyte.

\section{X-ray photoemission spectroscopy (XPS)}

X-ray photoemission spectroscopy (XPS) was performed in a custom-built ultrahigh-vacuum chamber, operating at a base pressure below $5 \times 10^{-9}$ mbar. A XM1200 monochromatic $\mathrm{X}$-ray source (Al K $\alpha$ line, Scienta Omicron) was used for X-ray excitation of the sample under a $45^{\circ}$ angle. Photoemitted electrons were collected using a HIPP-3 analyzer (Scienta Omicron). A polished platinum pellet (99.99\%, Kurt J. Lesker Company) was used for acquiring a Pt reference spectrum. Spectra were charge-corrected using the binding energy of $\mathrm{C} 1 \mathrm{~s}$ $(284.8 \mathrm{eV})$.

\section{Supporting Information}

Schematic description of the experimental process step by step for the Si nanostructures fabrication; XRD and ellipsometry data of the $\mathrm{TiO}_{2}$ layer; chronoamperometry measurements of $\mathrm{Si}$ nanocones with and without $\mathrm{TiO}_{2}$ layer; SEM image of Si nanocone after illumination without the $\mathrm{TiO}_{2}$ layer; current-vs-potential measurement on silicon nanocones; SEM images in and out of the illumination spot and of the illumination spot itself; representation of the photo-electrochemical cell; schematic diagram of the FDTD simulations and SEM images of more silicon nanostructures after photo-electrodeposition of platinum for verification of the effect.

\section{Supporting Information File 1}

Additional experimental data.

[https://www.beilstein-journals.org/bjnano/content/

supplementary/2190-4286-9-198-S1.pdf]

\section{Acknowledgements}

We thank Reinout Jaarsma (Advanced Research Center for Nanolithography - ARCNL institute) for his technical assistance with the XPS measurements. This work is part of the research program of the Foundation for Fundamental Research on Matter (FOM), which is financially supported by the Netherlands Organisation for Scientific Research (NWO).

\section{ORCID ${ }^{\circledR}$ iDs}

Evgenia Kontoleta - https://orcid.org/0000-0002-3327-1523

Sven H. C. Askes - https://orcid.org/0000-0001-6538-3645

Erik C. Garnett - https://orcid.org/0000-0002-9158-8326 


\section{References}

1. Landman, A.; Dotan, H.; Shter, G. E.; Wullenkord, M.; Houaijia, A.; Maljusch, A.; Grader, G. S.; Rothschild, A. Nat. Mater. 2017, 16, 646-651. doi:10.1038/nmat4876

2. Shi, Z.; Wen, X.; Guan, Z.; Cao, D.; Luo, W.; Zou, Z. Ann. Phys. 2015, 358, 236-247. doi:10.1016/j.aop.2015.04.005

3. Joya, K. S.; Joya, Y. F.; Ocakoglu, K.; van de Krol, R. Angew. Chem., Int. Ed. 2013, 52, 10426-10437. doi:10.1002/anie.201300136

4. Benson, E. E.; Kubiak, C. P.; Sathrum, A. J.; Smieja, J. M. Chem. Soc. Rev. 2009, 38, 89-99. doi:10.1039/B804323J

5. Li, J.; Wu, N. Catal. Sci. Technol. 2015, 5, 1360-1384. doi:10.1039/C4CY00974F

6. Bak, T.; Nowotny, J.; Rekas, M.; Sorrell, C. C. Int. J. Hydrogen Energy 2002, 27, 991-1022. doi:10.1016/s0360-3199(02)00022-8

7. Li, Z.; Feng, J.; Yan, S.; Zou, Z. Nano Today 2015, 10, 468-486. doi:10.1016/j.nantod.2015.06.001

8. Kamat, P. V. J. Phys. Chem. C 2007, 111, 2834-2860. doi:10.1021/jp066952u

9. Brongersma, M. L.; Cui, Y.; Fan, S. Nat. Mater. 2014, 13, 451-460. doi:10.1038/nmat3921

10. Atwater, H. A.; Polman, A. Nat. Mater. 2010, 9, 205-213. doi:10.1038/nmat2629

11. Wang, W.; Ramezani, M.; Väkeväinen, A. I.; Törmä, P.; Rivas, J. G.; Odom, T. W. Mater. Today 2018, 21, 303-314. doi:10.1016/j.mattod.2017.09.002

12. Landreman, P. E.; Chalabi, H.; Park, J.; Brongersma, M. L. Opt. Express 2016, 24, 29760. doi:10.1364/oe.24.029760

13. Cao, L.; Fan, P.; Vasudev, A. P.; White, J. S.; Yu, Z.; Cai, W.; Schuller, J. A.; Fan, S.; Brongersma, M. L. Nano Lett. 2010, 10, 439-445. doi:10.1021/n19036627

14. Wells, S. M.; Merkulov, I. A.; Kravchenko, I. I.; Lavrik, N. V.; Sepaniak, M. J. ACS Nano 2012, 6, 2948-2959. doi:10.1021/nn204110z

15. Grzela, G.; Paniagua-Domínguez, R.; Barten, T.; van Dam, D.; Sánchez-Gil, J. A.; Rivas, J. G. Nano Lett. 2014, 14, 3227-3234. doi:10.1021/nl5005948

16. Boriskina, S. V.; Ghasemi, H.; Chen, G. Mater. Today 2013, 16, 375-386. doi:10.1016/j.mattod.2013.09.003

17. Zheng, X.; Zhang, L. Energy Environ. Sci. 2016, 9, 2511-2532. doi:10.1039/C6EE01182A

18. Zhang, X.; Li, X.; Zhang, D.; Su, N. Q.; Yang, W.; Everitt, H. O.; Liu, J. Nat. Commun. 2017, 8, 14542. doi:10.1038/ncomms 14542

19. Wang, P.; Huang, B.; Dai, Y.; Whangbo, M.-H. Phys. Chem. Chem. Phys. 2012, 14, 9813. doi:10.1039/c2cp40823f

20. Zhang, Z.; Wang, Z.; Cao, S.-W.; Xue, C. J. Phys. Chem. C 2013, 117 25939-25947. doi:10.1021/jp409311x

21. Lu, Y.-C.; Xu, Z.; Gasteiger, H. A.; Chen, S.; Hamad-Schifferli, K.; Shao-Horn, Y. J. Am. Chem. Soc. 2010, 132, 12170-12171. doi:10.1021/ja1036572

22. Kim, H. J.; Kearney, K. L.; Le, L. H.; Haber, Z. J.; Rockett, A. A.; Rose, M. J. J. Phys. Chem. C 2016, 120, 25697-25708. doi:10.1021/acs.jpcc.6b08096

23. Zhou, L.; Zhang, C.; McClain, M. J.; Manjavacas, A.; Krauter, C. M.; Tian, S.; Berg, F.; Everitt, H. O.; Carter, E. A.; Nordlander, P.; Halas, N. J. Nano Lett. 2016, 16, 1478-1484. doi:10.1021/acs.nanolett.5b05149

24. Jiang, Z.; Zhang, Z.; Shangguan, W.; Isaacs, M. A.; Durndell, L. J.; Parlett, C. M. A.; Lee, A. F. Catal. Sci. Technol. 2016, 6, 81-88. doi:10.1039/C5CY01364J
25. Zhong, Z.; Ho, J.; Teo, J.; Shen, S.; Gedanken, A. Chem. Mater. 2007, 19, 4776-4782. doi:10.1021/cm071165a

26. Han, K. N.; Li, C. A.; Bui, M. P. N.; Pham, X. H.; Kim, B. S.; Choa, Y. H.; Seong, G. H. Sens. Actuators, B 2012, 174, 406-413. doi:10.1016/j.snb.2012.08.066

27. Li, R.; Zhang, F.; Wang, D.; Yang, J.; Li, M.; Zhu, J.; Zhou, X.; Han, H.; Li, C. Nat. Commun. 2013, 4, 1432. doi:10.1038/ncomms 2401

28. McDonald, K. J.; Choi, K.-S. Chem. Mater. 2011, 23, 1686-1693. doi: $10.1021 / \mathrm{cm} 1020614$

29. Zhong, D. K.; Cornuz, M.; Sivula, K.; Grätzel, M.; Gamelin, D. R. Energy Environ. Sci. 2011, 4, 1759. doi:10.1039/c1ee01034d

30. Taing, J.; Cheng, M. H.; Hemminger, J. C. ACS Nano 2011, 5, 6325-6333. doi:10.1021/nn201396v

31. Fernando, J. F. S.; Shortell, M. P.; Noble, C. J.; Harmer, J. R.; Jaatinen, E. A.; Waclawik, E. R. ACS Appl. Mater. Interfaces 2016, 8, 14271-14283. doi:10.1021/acsami.6b03128

32. Dasog, M.; Carim, A. I.; Yalamanchili, S.; Atwater, H. A.; Lewis, N. S. Nano Lett. 2016, 16, 5015-5021. doi:10.1021/acs.nanolett.6b01782

33. Krogstrup, P.; Jørgensen, H. I.; Heiss, M.; Demichel, O.; Holm, J. V.; Aagesen, M.; Nygard, J.; Fontcuberta i Morral, A. Nat. Photonics 2013, 7, 306-310. doi:10.1038/nphoton.2013.32

34. Schmitt, S. W.; Sarau, G.; Christiansen, S. Sci. Rep. 2015, 5, 17089. doi:10.1038/srep17089

35. Coenen, T.; van de Groep, J.; Polman, A. ACS Nano 2013, 7, 1689-1698. doi:10.1021/nn3056862

36. Lin, C.; Povinelli, M. L. Opt. Express 2009, 17, 19371. doi:10.1364/oe.17.019371

37. Wang, Z. Y.; Zhang, R. J.; Wang, S. Y.; Lu, M.; Chen, X.; Zheng, Y. X.; Chen, L. Y.; Ye, Z.; Wang, C. Z.; Ho, K. M. Sci. Rep. 2015, 5, 7810. doi:10.1038/srep07810

38. Scheuermann, A. G.; Prange, J. D.; Gunji, M.; Chidsey, C. E. D.; McIntyre, P. C. Energy Environ. Sci. 2013, 6, 2487. doi:10.1039/c3ee41178h

39. Shaner, M. R.; Hu, S.; Sun, K.; Lewis, N. S. Energy Environ. Sci. 2015, 8, 203-207. doi:10.1039/C4EE03012E

40. Hu, S.; Shaner, M. R.; Beardslee, J. A.; Lichterman, M.; Brunschwig, B. S.; Lewis, N. S. Science 2014, 344, 1005-1009. doi:10.1126/science.1251428

41. Bezares, F. J.; Long, J. P.; Glembocki, O. J.; Guo, J.; Rendell, R. W.; Kasica, R.; Shirey, L.; Owrutsky, J. C.; Caldwell, J. D. Opt. Express 2013, 21, 27587. doi:10.1364/oe.21.027587

42. Siefke, T.; Kroker, S.; Pfeiffer, K.; Puffky, O.; Dietrich, K.; Franta, D.; Ohlídal, I.; Szeghalmi, A.; Kley, E.-B.; Tünnermann, A. Adv. Opt. Mater 2016, 4, 1780-1786. doi:10.1002/adom.201600250

43. Lyon, L. A.; Hupp, J. T. J. Phys. Chem. B 1999, 103, 4623-4628. doi:10.1021/jp9908404

44. Kohtani, S.; Yoshida, K.; Maekawa, T.; Iwase, A.; Kudo, A.; Miyabe, H.; Nakagaki, R. Phys. Chem. Chem. Phys. 2008, 10, 2986. doi:10.1039/b719913a

45. Jiao, J.; Wei, Y.; Chi, K.; Zhao, Z.; Duan, A.; Liu, J.; Jiang, G.; Wang, Y.; Wang, X.; Han, C.; Zheng, P. Energy Technol. 2017, 5, 877-883. doi:10.1002/ente.201600572

46. Shuang, S.; Lv, R.; Xie, Z.; Zhang, Z. Sci. Rep. 2016, 6, 26670. doi:10.1038/srep26670

47. Hodes, G.; Kamat, P. V. J. Phys. Chem. Lett. 2015, 6, 4090-4092. doi:10.1021/acs.jpclett.5b02052

48. Chi, J. Y.; Gatos, H. C. J. Appl. Phys. 1979, 50, 3433-3440. doi:10.1063/1.326336 


\section{License and Terms}

This is an Open Access article under the terms of the Creative Commons Attribution License

(http://creativecommons.org/licenses/by/4.0). Please note that the reuse, redistribution and reproduction in particular requires that the authors and source are credited.

The license is subject to the Beilstein Journal of Nanotechnology terms and conditions:

(https://www.beilstein-journals.org/bjnano)

The definitive version of this article is the electronic one which can be found at:

doi:10.3762/bjnano.9.198 